\title{
THE EFFECTIVENESS OF ADAPTING THE 5E MODEL CYCLES AS DAILY LESSON PLANS AND USES FOR LESSON DELIVERY PROCESSES IN TEACHING BIOLOGY
}

\author{
Sutuma Edessa \\ Addis Ababa University, Ethiopia
}

\begin{abstract}
The aim of the research was to adapt the 5E model cycles as daily lesson plans, uses for biology lesson delivery processes and evaluate its effectiveness in comparison with the uses of classical steps of daily lesson plans.

Quasi-experimental method was used to identify variables of data collections in which recognized variables were set to compose of 1-5 rated score checklists. The 5E model cycles were adapted as daily lesson delivery processes instead of the classical steps of teaching biology that 40 trainees of biology teaching conducted peer-teaching twice using both the newly designed and the classical steps in four Colleges of Teacher Education of Ethiopia, whereby the effectiveness of using both the processes of daily lesson plans were evaluated comparatively.

As a result, adapting the $5 E$ model cycles for lesson delivery process was $50.65 \%$ more effective than using the classical steps in the process of teaching biology.

The research was concluded by the fact that adapting the 5E model cycles in biology lesson delivery process played significant roles to carry out classroom discussions confidentially, construct conceptual understanding and self preparedness in learning to conduct practical education.

Keywords: knack, lesson plans, peer-teaching, rated scores, variables.
\end{abstract}

\section{Introduction}

The ever increasing demand for the quality education that secures job opportunity and better living standards is one of the outstanding issues of any society. Quality educational systems that include teaching, learning and assessment techniques need standardized practical knowledge. The teacher as a major role player in any education systems needs to undergo trainings to acquire proper personal and professional qualities.

In view of this, the ministry of Education of Ethiopia (1999) commented that professionalism tends to be weak among teachers in developing countries, because the criteria of a true profession are not completely met. It is mostly caused by the lack of sufficient training and rich experiences, which is actually true among many Ethiopian teachers serving from elementary through Primary, Secondary and Tertiary schools.

In describing the roles of teachers in providing quality education system and the importance of professionalism, Love Grove, N.S. (1963) cited in Rousseau; reads as "Remember you must be a man yourself before you try to train a man. You yourself must set pattern he shall copy".

The statement underscores the need for being readiness of teachers before they embark on teaching and preparations of supportive materials for lesson delivery process including the lesson planning. Lesson planning is designing the "how" and the "what" of delivery process of a topic or portions of a prescribed text within the school time budget and carry out the process with confidence to reach at good conclusions.

Teaching is humanizing a man, but it is the most difficult task that everybody doesn't fit. Some persons have a flair for teaching and some, who are not fortunate, can improve their teaching through training or practices. The level of expectations of people to 
change their life conditions that enable graduates to work and live with the satisfaction of needs and wants from learning biology requires more improvements on the current biology education systems.

However, the working education systems of the country are limited to more of lecture methods and could not develop the education systems into practical knowledge. Learning scientific knowledge in a conceptually integrated and useful form is not an easy process for most students (Uttam Kumar Singh \& Nayak, 2005).

One of the teaching materials of the working school curricula is the daily lesson plan through which the lesson delivery process could be successful and fruitful, but currently, lacks involvements in the delivery process of designated biology lessons as prescribed in the texts.

According to Yadav (2004), a proper planning of a lesson is a key to effective teaching in which the teacher must know in advance the subject matter and the mode of its delivery in the classroom. Education is a social service and teachers should have to have a knack for teaching (Griffiths, 1962).

Although the working daily lesson plan consists of proper sequential lesson delivery steps termed as Introduction, Presentation, Recapitulation, Discussion and Evaluation, the implementation of the process mostly sticks to teacher-centeredness or theoretical coverage of portions in which learners are not engaged into practical activities and remain neglected. It could not actually facilitate the steps to serve as arts of teaching in obliging learners to critically think, rethink and reach at good conclusions.

One of the qualities of the daily lesson plans is the procedure; the part which one sets forth what the teacher and students will do during the lessons (Callahan \& Clark, 1988). According to Bybee et al, (2006), the 5E model cycles provide specific functions and contribute coherent instructions to the teachers as well as a better understanding of scientific and technological knowledge, attitudes and skills formulation to learners.

Among numberless flourishing teaching models, the 5E model cycles were selected to replace the working daily lesson plan steps and designed to be used practically for biology lesson delivery process to provide quality education.

The 5E model cycles serve as a voyage though time instruction model and tool based on the constructive approach to learning and enhances learners to build up new ideas on top of their old ideas (Bybee, 1966). The 5E model composes of five memorable wording cyclical phases beginning with the letter E: Engagement, Exploration, Explanation, Elaboration and Evaluation, which were adapted to design new daily lesson for lesson delivery process and solve the problem ineffective teaching of biology.

The issue of the research was to use the newly designed daily lesson plan for biology lesson delivery process and evaluates its effectiveness against the working steps of daily lesson plan.

\section{Research Methodology}

The research was conducted in four Colleges of Teacher Education (CTE) of Bonga, Harer, Kemise and Nekemte of Ethiopia. Candidates join the Colleges for three consecutive years to undergo training in subjects they prefer or integrated sciences after passing grade 10 National Examination. Among biology teaching trainees, top 10 of the graduating classes were selected from each College $(10 \times 4=40)$ based on their stratified and ratified post credentials achieved through 5 semesters with equal gender parity composing 
of 5 females and 5 males as research population.

Consequently, a new daily lesson plan was designed by replacing the common elements of working daily lesson with the following $5 \mathrm{E}$ model cycles in the steps of each phase of lesson delivery within the given time budget (Appendix 1).

1. Engagement: stimulates the interest of students to get involved in the activities and make connections between past and present learning experiences.

2. Exploration: learners build up clear understanding through involvement with materials, work together and investigate new learning process, test, maintain and reach at conclusions of critical thinking.

3. Explanation: provides learners with opportunities to communicate with what they had learned so far and figure out meanings.

4. Elaboration: allows learners to use the new knowledge and continue to discover, expand the concepts and apply.

5. Evaluation: determines if learners had attained understanding of concepts and knowledge.

The working daily lesson plans composing of 5 elements serving as steps of lesson delivery in the daily lesson plans were reconstructed to be used for comparison visa-vise the effectiveness of using the 5E model cycles for teaching biology (Appendix 2).

1. Introduction: uses to commence the daily lesson with clear and precise information to motivate learners and arrest their attention.

2. Presentation: deals with the uses of proper teaching methods and tangible supportive materials to carry out the daily lesson.

3. Recapitulation: consolidates the daily lesson contents.

4. Discussion: refines and clears out doubts of the delivered lesson contents and revisits uncovered portions to make every concept fine and understandable.

5. Assessments: checks to what extent learners have understood the lessons.

Accordingly, the selected trainees of teaching biology in each College of Teacher Education (CTE) were provided short orientations on how to practically use both daily lesson plans for biology lesson delivery through peer-teaching. All selected 40 trainees of biology teaching of the graduating practically conducted peer-teaching twice using daily lesson plans, once adapting the newly designed daily lesson plans from 5E model cycles and second, using the reconstructed working steps of daily lesson plan in each round of peer-teaching. In both round peer-teachings, both types of lesson plans served as teaching tools and each phase or step of the lesson plan was used as variables of data collection.

Quasi-experiment is one of the research methods that support to identify variables for collecting required data and related evidences (Gibbons, et al, 1997). Hence, a quasi-experimental method was employed to identify variables of data collection. Data were collected through variables on the effectiveness of using both types of daily lesson plans by each trainee for each conducted peer-teaching in each College that the extent of effectiveness of using both tools were evaluated using purposely set checklists composing of 1-5 rated score variables (tables1-8).

\section{Data Analysis}

In classroom teaching and learning processes, a dramatic situation comes to the scenery of interactions between the teacher and the students. Evaluation of such teaching and learning process in the classrooms is a rigorous task to make attempt. 
Nonetheless, empirical data were collected while selected 40 trainees conducted peer-teaching using both types of daily lesson plans in each CTE. Consequently, in Bonga CTE, the average value of using cycles or phases of the $5 \mathrm{E}$ model adapted to daily lesson was $92 \%$ against the $30 \%$ of using classical steps; whereas the difference of rated scores showed $62 \%$ effectiveness (tables 1 and 2 ).

In Harer CTE, the average rated score of adapting the 5E model cycles for lesson delivery was $96 \%$ against the $48.3 \%$ of using the classical steps of the daily lesson plans showing $47.7 \%$ effectiveness.

In Kemise CTE, the average rated score value of adapting the 5E model cycles for biology lesson delivery was $88 \%$ against the $30 \%$ of using the classical steps of the daily lesson plans and made 58\% effectiveness in teaching biology.

In Nekemte CTE, the average rated score value of adapting the 5E model cycles for biology lesson delivery was $98 \%$ against the $58.2 \%$ of using the classical daily lesson plan that made $39.8 \%$ effectiveness in teaching biology.

\section{Research Results}

As a result of research conducted in four CTEs, the effectiveness of adapting the $5 \mathrm{E}$ model cycles for biology lesson delivery was evaluated vise-a-vise the uses of the classical steps of teaching biology and recorded as follows (tables 1-9) .

\section{Bonga CTE}

Table 1. Checklist for evaluating the adaption of $5 \mathrm{E}$ model cycles.

\begin{tabular}{|l|l|l|l|l|l|l|l|l|l|}
\hline \multirow{2}{*}{ Steps } & \multirow{2}{*}{ 5E model cycles } & \multicolumn{7}{|l|}{ Rated scores of effectiveness of variables } \\
\cline { 3 - 12 } & & 1 & 2 & 3 & 4 & 5 & Average & $100 \%$ \\
\hline 1 & Engagement & $\sqrt{ }$ & $\sqrt{ }$ & $\sqrt{ }$ & $\sqrt{ }$ & $\sqrt{ }$ & & \\
\hline 2 & Exploration & $\sqrt{ }$ & $\sqrt{ }$ & $\sqrt{ }$ & $\sqrt{ }$ & $\sqrt{ }$ & & \\
\hline 3 & Explanation & $\sqrt{ }$ & $\sqrt{ }$ & $\sqrt{ }$ & $\sqrt{ }$ & $\sqrt{ }$ & & \\
\hline 4 & Elaboration & $\sqrt{ }$ & $\sqrt{ }$ & $\sqrt{ }$ & $\sqrt{ }$ & & & \\
\hline 5 & Evaluation & $\sqrt{ }$ & $\sqrt{ }$ & $\sqrt{ }$ & $\sqrt{ }$ & & & \\
\hline & Score average & 1 & 2 & 3 & 4 & $3 / 5$ & $4.6 / 5$ & 92 \\
\hline
\end{tabular}


Table 2. Checklist for evaluating the uses of classical steps.

\begin{tabular}{|c|c|c|c|c|c|c|c|c|}
\hline \multirow{2}{*}{ Steps } & \multirow{2}{*}{ Lesson plan variables } & \multicolumn{7}{|c|}{ Rated scores of effectiveness of variables } \\
\hline & & 1 & 2 & 3 & 4 & 5 & Average & $100 \%$ \\
\hline 1 & Introduction & $\sqrt{ }$ & $\sqrt{ }$ & & & & & \\
\hline 2 & Presentation & $\sqrt{ }$ & & & & & & \\
\hline 3 & Recapitulation & $\sqrt{ }$ & & & & & & \\
\hline 4 & Discussion & $\sqrt{ }$ & & & & & & \\
\hline \multirow[t]{2}{*}{5} & Evaluation & $\sqrt{ }$ & & & & & & \\
\hline & Score average & 1 & 0.5 & & & & $1.5 / 5$ & 30 \\
\hline
\end{tabular}

\section{Harer CTE}

Table 3. Checklist for evaluating the adaption of $5 \mathrm{E}$ model cycles.

\begin{tabular}{|l|l|l|l|l|l|l|l|l|}
\hline \multirow{2}{*}{ Steps } & \multirow{2}{*}{$\begin{array}{l}\text { 5E model } \\
\text { cycles }\end{array}$} & \multicolumn{6}{|l|}{ Rated scores of effectiveness of variables } \\
\cline { 3 - 11 } & 1 & 2 & 3 & 4 & 5 & Average & $100 \%$ \\
\hline 1 & Engagement & $\sqrt{ }$ & $\sqrt{ }$ & $\sqrt{ }$ & $\sqrt{ }$ & $\sqrt{ }$ & & \\
\hline 2 & Exploration & $\sqrt{ }$ & $\sqrt{ }$ & $\sqrt{ }$ & $\sqrt{ }$ & $\sqrt{ }$ & & \\
\hline 3 & Explanation & $\sqrt{ }$ & $\sqrt{ }$ & $\sqrt{ }$ & $\sqrt{ }$ & $\sqrt{ }$ & & \\
\hline 4 & Elaboration & $\sqrt{ }$ & $\sqrt{ }$ & $\sqrt{ }$ & $\sqrt{ }$ & $\sqrt{ }$ & & \\
\hline 5 & Evaluation & $\sqrt{ }$ & $\sqrt{ }$ & $\sqrt{ }$ & $\sqrt{ }$ & & & \\
\hline & Score average & 1 & 2 & 3 & 4 & $4 / 5$ & $4.8 / 5$ & 96 \\
\hline
\end{tabular}

Table 4. Checklist for evaluating the uses of classical steps.

\begin{tabular}{|l|l|l|l|l|l|l|l|l|l|}
\hline \multirow{2}{*}{ Steps } & \multirow{2}{*}{ Lesson plan variables } & \multicolumn{6}{|l|}{ Rated scores of effectiveness of variables } \\
\cline { 3 - 11 } & & 1 & 2 & 3 & 4 & 5 & Average & $100 \%$ \\
\hline 1 & Introduction & $\sqrt{ }$ & $\sqrt{ }$ & $\sqrt{ }$ & & & & \\
\hline 2 & Presentation & $\sqrt{ }$ & $\sqrt{ }$ & $\sqrt{ }$ & & & & \\
\hline 3 & Recapitulation & $\sqrt{ }$ & $\sqrt{ }$ & & & & & \\
\hline 4 & Discussion & $\sqrt{ }$ & $\sqrt{ }$ & & & & & \\
\hline 5 & Evaluation & $\sqrt{ }$ & $\sqrt{ }$ & & & & & \\
\hline & Score average & 1 & 2 & $2 / 3$ & & & $2.66 / 5$ & 48.3 \\
\hline
\end{tabular}

Kemise CTE 
Table 5. Checklist for evaluating the adaption of $5 \mathrm{E}$ model cycles.

\begin{tabular}{|l|l|l|l|l|l|l|l|l|l|}
\hline \multirow{2}{*}{ Steps } & \multirow{2}{*}{ Lesson plan variables } & \multicolumn{7}{|c|}{ Rated scores of effectiveness of variables } \\
\cline { 3 - 11 } & & 1 & 2 & 3 & 4 & 5 & Average & $100 \%$ \\
\hline 1 & Engagement & $\sqrt{ }$ & $\sqrt{ }$ & $\sqrt{ }$ & $\sqrt{ }$ & $\sqrt{ }$ & & \\
\hline 2 & Exploration & $\sqrt{ }$ & $\sqrt{ }$ & $\sqrt{ }$ & $\sqrt{ }$ & & & \\
\hline 3 & Explanation & $\sqrt{ }$ & $\sqrt{ }$ & $\sqrt{ }$ & $\sqrt{ }$ & $\sqrt{ }$ & & \\
\hline 4 & Elaboration & $\sqrt{ }$ & $\sqrt{ }$ & $\sqrt{ }$ & $\sqrt{ }$ & $\sqrt{ }$ & & \\
\hline 5 & Evaluation & $\sqrt{ }$ & $\sqrt{ }$ & $\sqrt{ }$ & & & & \\
\hline & Score average & 1 & 2 & 3 & 0.8 & 0.6 & $4.4 / 5$ & 88 \\
\hline
\end{tabular}

Table 6. Checklist for evaluating the uses of classical steps.

\begin{tabular}{|c|c|c|c|c|c|c|c|c|}
\hline \multirow{2}{*}{ Steps } & \multirow{2}{*}{ Lesson plan variables } & \multicolumn{7}{|c|}{ Rated scores of effectiveness of variables } \\
\hline & & 1 & 2 & 3 & 4 & 5 & Average & $100 \%$ \\
\hline 1 & Introduction & $\sqrt{ }$ & & & & & & \\
\hline 2 & Presentation & $\sqrt{ }$ & & & & & & \\
\hline 3 & Recapitulation & $\sqrt{ }$ & & & & & & \\
\hline 4 & Discussion & $\sqrt{ }$ & & & & & & \\
\hline \multirow[t]{2}{*}{5} & Evaluation & $\sqrt{ }$ & $\sqrt{ }$ & & & & & \\
\hline & Score average & 1 & $1 / 2$ & & & & $1.5 / 5$ & 30 \\
\hline
\end{tabular}

Nekemte CTE

Table 7. Checklist for evaluating the adaption of $5 \mathrm{E}$ model cycles.

\begin{tabular}{|l|l|l|l|l|l|l|l|l|l|}
\hline \multirow{2}{*}{ Steps } & \multirow{2}{*}{ Lesson plan variables } & \multicolumn{6}{|l|}{ Rated scores of effectiveness of variables } \\
\cline { 3 - 11 } & & 1 & 2 & 3 & 4 & 5 & Average & $100 \%$ \\
\hline 1 & Engagement & $\sqrt{ }$ & $\sqrt{ }$ & $\sqrt{ }$ & $\sqrt{ }$ & $\sqrt{ }$ & & \\
\hline 2 & Exploration & $\sqrt{ }$ & $\sqrt{ }$ & $\sqrt{ }$ & $\sqrt{ }$ & $\sqrt{ }$ & & \\
\hline 3 & Explanation & $\sqrt{ }$ & $\sqrt{ }$ & $\sqrt{ }$ & $\sqrt{ }$ & $\sqrt{ }$ & & \\
\hline 4 & Elaboration & $\sqrt{ }$ & $\sqrt{ }$ & $\sqrt{ }$ & $\sqrt{ }$ & & & \\
\hline 5 & Evaluation & $\sqrt{ }$ & $\sqrt{ }$ & $\sqrt{ }$ & $\sqrt{ }$ & $\sqrt{ }$ & & \\
\hline & Score average & 1 & 2 & 3 & 4 & $4.5 / 5$ & $4.9 / 5$ & 98 \\
\hline
\end{tabular}


Table 8. Checklist for evaluating the uses of classical steps.

\begin{tabular}{|l|l|l|l|l|l|l|l|l|}
\hline \multirow{2}{*}{ Steps } & \multirow{2}{*}{ Lesson plan variables } & \multicolumn{6}{|l|}{ Rated scores of effectiveness of variables } \\
\cline { 3 - 11 } & & 1 & 2 & 3 & 4 & 5 & Average & $100 \%$ \\
\hline 1 & Introduction & $\sqrt{ }$ & $\sqrt{ }$ & $\sqrt{ }$ & $\sqrt{ }$ & & & \\
\hline 2 & Presentation & $\sqrt{ }$ & $\sqrt{ }$ & & & & & \\
\hline 3 & Recapitulation & $\sqrt{ }$ & $\sqrt{ }$ & & & & & \\
\hline 4 & Discussion & $\sqrt{ }$ & $\sqrt{ }$ & & & & & \\
\hline 5 & Evaluation & $\sqrt{ }$ & $\sqrt{ }$ & $\sqrt{ }$ & & & & \\
\hline & Score average & 1 & 2 & $2 / 3$ & $1 / 4$ & & $2.91 / 5 / 10$ & 58.2 \\
\hline
\end{tabular}

Table 9. Summary of evaluation on the effectiveness of using both tools in four CTE.

\begin{tabular}{|l|l|l|l|}
\hline CTE & $\begin{array}{l}\text { Effectiveness of using the } \\
\text { classical steps of teaching }\end{array}$ & $\begin{array}{l}\text { Effectiveness of using } \\
\text { the 5E model cycles }\end{array}$ & $\begin{array}{l}\text { Difference in } \\
\text { effectiveness }\end{array}$ \\
\hline Bonga & $30 \%$ & $92 \%$ & $62 \%$ \\
\hline Harer & $53.2 \%$ & $96 \%$ & $48.2 \%$ \\
\hline Kemise & $30 \%$ & $88 \%$ & $58 \%$ \\
\hline Nekemte & $58.2 \%$ & $98 \%$ & $39.8 \%$ \\
\hline Total & $171.4 \%$ & $374 \%$ & $202.6 \%$ \\
\hline Average & $42.85 \%$ & $93.5 \%$ & $50.65 \% \%$ \\
\hline
\end{tabular}

The average effectiveness value of adapting the 5E model cycles into daily lesson plans and uses for biology lesson delivery was $93.5 \%$ against the $42.85 \%$ of using classical steps that resulted with effectiveness of $50.65 \%$ and that much solved the problems of teaching of biology.

\section{Conclusions}

Adapting the 5E model cycles in the daily lesson and using for biology lesson delivery has solved the problem of teaching biology by more than $50 \%$, which is one of the best effectiveness of teaching process that could operate in all subjects too. Designing the daily lesson plans using the 5E model cycles and properly implementations generated interests of learners that led them to explore and understand something familiar in greater depth and constructed knowledge to unexpected extent.

As a matter of fact, the outcome of the research proved that changes in the steps of lesson delivery played significant roles and facilitated in improving the quality of lesson presentation, leading classroom discussion, executing practical activities and learning by doing of students. 
Finally, it was found out as one of the best biology teaching tools that radically changed the expectations of both teachers and learners, made the learning environment conducive, supported to build self-confidence and solved the problem of poor biology lesson delivery.

\section{References}

Bybee, R. W. et al (2006). The biological science curriculum study $5 E$ instructional model: Origins, effectiveness and applications. Executive summary, 5415 Mark Dabbling Boulevard, Colorado Springs, CO 80918, www.bscs.org.

Bybee, R. W. (1966). National standards and the science curriculum: Challenges, opportunities and recommendations. Dubuque, Iowa, USA: Kendall-Hunt Publishers.

Gribbons, B., \& Herman, J. (1997). True and quasi-experimental designs. Practical Assessments, Research and Evaluation, 5 (14), 1-3. Retrieved from https://pareonline.net/getvn. asp? $\mathrm{v}=5 \% 26 \mathrm{n}=14$.

Griffiths, V. L. (1962). Educational planning. London: Oxford University press.

Callahan, J. F., \& Clark, L. H. (1988). Teaching in the middle and secondary schools. Planning for competence. Third Edition. USA: Macmillan Publishing.

Love grove, N. S. (1963). The quality of teaching. A Handbook for teachers who intended becoming teachers and for those interested in teacher education of children. Ministry of Education and Fine Arts, Ethiopia.

Ministry of Education (1999). Teacher education Handbook. Institute for Curriculum Development and Research. Addis Ababa, Ethiopia.

Uttam Kumar Singh, \& Nayak, A. K. (2005). Teaching of science. New Delhi, India: Commonwealth Publishers, Roshan offset printers.

Yadav, M. S. (2004). Teaching of Science. Anmol publications PVT.LTD. New Delhi, India.

Appendices

Appendix A

The $5 \mathrm{E}$ model cycles incorporated in a daily lesson plan

\begin{tabular}{|l|l|}
\hline Teacher's name: & School: \\
\hline Subject: & Date of lesson: \\
\hline Students: Male $\quad$ Female Total & Grade: \\
\hline Lesson topic: & \\
\hline
\end{tabular}

Specific objectives: at the end of the lesson, the students will be able to:

1.

2.

3.

4.

5.

Specific teaching methods:

Specific teaching aids: 


\begin{tabular}{|l|l|l|}
\hline Teacher's activities & 'Students' activities \\
\hline Engagement: & & \\
\hline Exploration: & & \\
\hline Explanation: & & \\
\hline Elaboration: & & \\
\hline $\begin{array}{l}\text { Evaluation: } \\
\text { 2. } \\
\text { 3. } \\
\text { 4. } \\
\text { 5. }\end{array}$ & & \\
\hline
\end{tabular}

Appendix B

The common elements of a daily lesson plan

\begin{tabular}{|c|c|c|}
\hline Teacher's name: & & School: \\
\hline Subject: & & Date of lesson: \\
\hline Students: Male & Total & Grade: \\
\hline \multicolumn{3}{|l|}{ Lesson topic: } \\
\hline $\begin{array}{l}\text { Specific objectives: at the end of t } \\
1 . \\
2 . \\
3 . \\
4 . \\
5 .\end{array}$ & esson, t & ents will be able to: \\
\hline \multicolumn{3}{|l|}{ Specific teaching methods: } \\
\hline \multicolumn{3}{|l|}{$\overline{\text { Specific teaching aids: }}$} \\
\hline Teacher's activity & & Students' activity \\
\hline
\end{tabular}




\begin{tabular}{|l|l|l|}
\hline Introduction: & & \\
\hline Presentation: & & \\
\hline Recapitulation: & & \\
\hline $\begin{array}{l}\text { Discussion: } \\
\text { Assessments: }\end{array}$ & & \\
\hline $\begin{array}{l}\text { 2. } \\
\text { 3. }\end{array}$ & & \\
\hline $\begin{array}{l}\text { 4. } \\
5 .\end{array}$ & & \\
\hline
\end{tabular}

Received 28 April 2019; Accepted 22 June 2019

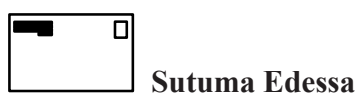

PhD., Science and Mathematics Education, College of Education and Behavioral Studies, Addis Ababa University, Ethiopia.

E-mail: Sutuma2002@yahoo.com 